Article

\title{
Application of Terrestrial Laser Scanner to Evaluate the Influence of Root Collar Geometry on Stump Height after Mechanized Forest Operations
}

\author{
Eric R. Labelle ${ }^{1, *(\mathbb{D})}$, Joachim B. Heppelmann ${ }^{1}$ and Herbert Borchert ${ }^{2}$ \\ 1 Department of Ecology and Ecosystem Management, Technical University of Munich, \\ Hans-Carl-von-Carlowitz-Platz 2, D-85354 Freising, Germany; joachim.heppelmann@hswt.de \\ 2 Bayerische Landesanstalt für Wald und Forstwirtschaft, Hans-Carl-von-Carlowitz-Platz 1, \\ D-85354 Freising, Germany; herbert.borchert@lwf.bayern.de \\ * Correspondence: eric.labelle@tum.de; Tel.: +49-816-171-4760
}

Received: 26 October 2018; Accepted: 14 November 2018; Published: 15 November 2018

\begin{abstract}
The height of tree stumps following mechanized forest operations can be influenced by machine-, tree-, terrain-, and operator-related characteristics. High stumps may pose different economic and technical disadvantages. Aside from a reduction in product recovery (often associated with sawlog potential), leaving high stumps can complicate future entries if smaller equipment with low ground clearance is used, particularly in the case where new machine operating trails are required. The objective of this exploratory study was to examine if correlations existed between the height of tree stumps following mechanized harvesting and the shape of the above-ground root collar, stump diameter, and distance to the machine operating trail. In total, 202 sample stumps of Norway spruce (Picea abies (L.) Karst.) and the surrounding terrain were scanned with a terrestrial laser scanner. The collected data was processed into a 3D-model and then analyzed. Stump height was compared with different characteristics such as stump diameter at the cut surface, distance to the machine operating trail, number of visible root flares per stump, and the root collar. The number of root flares per stump had a positive influence on stump diameter and height, showing a general trend of increasing diameter and height with the increasing number of root flares. Root angles also had an influence on the stump diameter. The diameter of a stump and the shape of the root collar at the cut surface together had a significant effect on stump height and the model reported explained half of the variation of stump heights. Taken together, these findings suggest that other factors than the ones studied can also contribute in influencing stump height during mechanized harvesting operations. Further investigations, including pre- and post-harvest scans of trees selected for removal, are warranted.
\end{abstract}

Keywords: stump diameter; stump height; harvester; product recovery; Norway spruce

\section{Introduction}

A recent change in German forestry has been the increased use of mechanized forest operations, particularly when considering the cut-to-length (CTL) method [1]. In a fully mechanized CTL system, a harvester is commonly used to fell, delimb, and buck the stem into logs of various lengths directly on the machine operating trail after which a forwarder is used to transport the processed logs to the roadside or to a landing area. Harvesters were first introduced in Germany during the 1990 large-scale wind-throws, which uprooted about 72.5 million $\mathrm{m}^{3}$ of wood and required a sudden widespread increase of mechanized operations to safely and efficiently harvest the unusually large amount of wood [2]. Nowadays, hundreds of harvesters are in use in Germany and they are the most 
common machines encountered in mechanized operations [3]. The proven benefits of fully-mechanized harvesting systems are the increased work safety, the combination of different working steps into one process, and increased monetary profits via higher productivity and efficiency [4]. Currently, about $60 \%$ of all wood harvested from German public forests is with mechanized forest operations and from this proportion, the entirety is with the cut-to-length (CTL) method [1]. While tree size and shape have less influence on the feasibility of chainsaw operations, harvesters can reach their operational limit with large diameter trees or with trees exhibiting relatively large diameters and complex root systems, thus potentially leaving high stumps in the forest. Such stumps can be unwanted obstacles making it difficult to maneuver machines through the forest or transport wood without damaging residual trees. Additionally, the Food and Agriculture Organization of the United Nations suggests stump height should be as low as practicable and identifies $30 \mathrm{~cm}$ or lower as a preferable threshold to maximize merchantable volume [5]. With advancements in machine design and with specific requirements from third-party certification programs, it is not uncommon to see alterations in the design/layout of machine operating trails. Any modification in spatial alignment or spacing of machine operating trails will entail that some new trails have to be created in areas that were previously in the leave strip (area adjacent to two trails). It should also be of interest to harvest as much woody biomass as possible and produce logs of longer length, especially in the lower section of the tree, where the diameter is the greatest and normally presents fewer irregularities and, thus, providing higher returns.

Concerning woody biomass, measurements done throughout the last century were mostly performed manually with simple techniques, tables, and often relying on estimations rather than actual measurements. The terrestrial laser scanner (TLS), on the other hand, provides a relatively easy, fast, and precise method to scan and measure forest structures by sending out an infrared laser beam scanning the surrounding environment on the millimeter scale. This is of particular importance when the scanning subjects have an irregular shape, such as tree stumps. The TLS is a non-intrusive and non-destructive measurement device that allows for repeated measurements at the exact same locations. Initially developed to address issues in the industrial building sector, the use of TLS in forestry settings is increasing in frequency. TLS data have already been used to estimate forest structures such as sub-canopy architecture [6], leaf area index [7-9], tree height, diameter and diameter at breast height [10-15], and specific tree properties, such as stem volume [14] and crown characteristics [16-19]. Regarding stump measurements, TLS was used to assess above-ground stump biomass and the associated indirect emission of bioenergy [20]. The most noticeable advantages of this system are the possibilities of capturing data without disturbing the forest environment. Once recorded, the data can be used to measure variables of interest without the need to revisit the study area if further information is missing. Despite the research and advancements listed above, very limited research has been completed with TLS to measure stump characteristics in order to investigate the influence of above-ground root collar on stump height following mechanized felling.

To allow mechanized forest operations to be as effective as possible, it is necessary to identify and understand physical barriers that might influence the height at which a tree can be cut and felled. Such a barrier might be the stump diameter. Each harvesting head has a limited range of stem diameters which can be cut. The diameter can be limited either by the opening of the feed-rollers or the length of the saw bar. If the diameter close to the ground is too large, the harvesting head can be lifted upwards until a suitable diameter is reached, thereby creating a higher stump. Striking root flares might also hinder an adjustment of the harvesting head close to the ground. Together with an increasing distance from the machine, the lifting force of the harvester boom decreases. Some harvesters can hardly lift the harvesting head alone if the boom is fully extended. In this case, a proper arrangement of the harvesting head at the tree is difficult. At greater distances, the visibility of operators can also be hindered. Both might contribute to higher stumps with an increasing distance between the machine operating trail and the tree.

In the scope of this study, we intended to test the following hypotheses: 
Hypothesis 1. We anticipate a correlation between stump height and stump diameter, which will lead to higher stumps as the diameter at the cut surface is increasing.

Hypothesis 2. We anticipate a correlation between the distance from a stump to the machine operating trail and stump height resulting in higher stumps as the distance between the stump and trail is increasing.

Hypothesis 3. We also anticipate a correlation between stump diameter and root collar, which will lead to a higher stump diameter as the root angles are getting flatter and are, therefore, also causing higher stumps.

Through the use of a TLS, the objective of this study was to find possible correlations between stump height and physical parameters, such as stump diameter, above-ground root collar, and distance to the machine operating trail following mechanized operations. In this context, we defined a root collar as the above-ground widening of the stump beyond its natural taper.

Other factors may also affect stump height. This can be the power of the harvester, the skill of the operator or the tree species being harvested. These factors can only be analyzed when a large number of different logging operations are observed. However, we investigated the stumps of only one logging operation and could, therefore, not address the above-mentioned factors.

\section{Materials and Methods}

\subsection{Research Site and Experimental Design}

Research sites were located in southern Germany near the town of Freising (Figure 1A). In total, 103 stumps were measured in the forest district Rappenberg $\left(48^{\circ} 24^{\prime} 25.2^{\prime \prime} \mathrm{N}\right.$ and $\left.11^{\circ} 42^{\prime} 19.6^{\prime \prime} \mathrm{E}\right)$ and 99 stumps in the neighboring district Wippenhausereinfang $\left(48^{\circ} 25^{\prime} 33.1^{\prime \prime} \mathrm{N}\right.$ and $\left.11^{\circ} 41^{\prime} 13.6^{\prime \prime} \mathrm{E}\right)$. The sites were chosen because of the fully-mechanized operations and their proximity to the Technical University of Munich. Mechanized harvesting was performed in February and March 2015 by an experienced entrepreneur commissioned by the Bavarian State Forest Enterprise to harvest trees following a wind-throw. This calamity triggered an opportunity to perform additional thinning operations near the affected areas. However, only the trees that showed no sign of wind-throw were analyzed in this study. To exclude the influences of different mechanical specifications, the study area only involved the sections harvested by the same machine and operator.

A

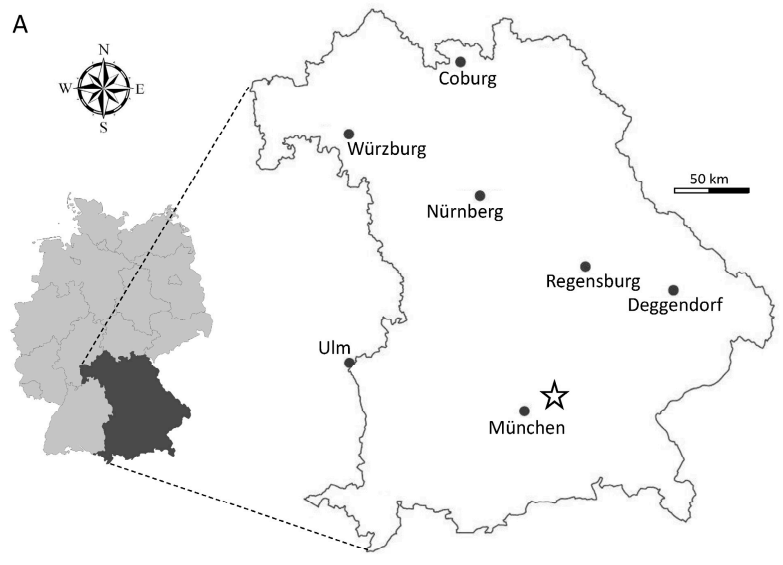

B

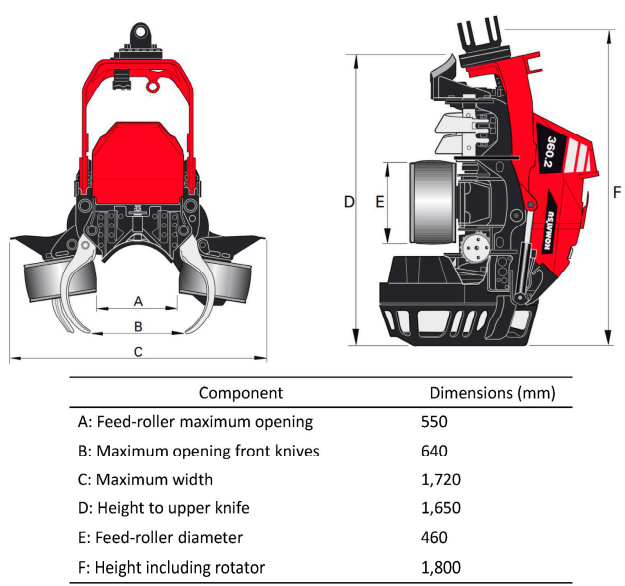

Figure 1. (A). Location of research sites depicted by star symbol within the State of Bavaria, Germany; (B). Top and side-view of a Komatsu 360.2 harvesting head along with dimensions of the main components [21].

The forest is mainly stocked with Norway spruce (Picea abies) (80\%) and European beech (Fagus sylvatica L.) (15\%) mixed with a few Douglas fir (Pseudotsuga menziesii (Mirb.) Franco), larch (Larix 
decidua Mill.) and oak (Quercus L.) trees constituting the remaining 5\%. The mechanized portion of the felling and our associated measurements were performed in a Norway spruce-dominated stand. For this study, stumps originating from 202 harvester-felled Norway spruce trees with varying diameters along with the corresponding machine operating trails and surrounding forest areas were scanned with a TLS. The only stumps targeted were those that were (i) not affected by the wind-throw and, thus, possessed an undisturbed root collar and (ii) stumps originating from the current harvest. Due to the very limited spatial extent of the test site, similar stand and terrain conditions were present.

All of the 202 trees corresponding to our sampled stumps had previously been harvested and processed with a Valmet 921 (Komatsu Forest AB, Umea, Sweden) six-wheeled single-grip harvester with a $10 \mathrm{~m}$ long boom equipped with a Komatsu forest 360.2 harvesting head (Komatsu Forest AB, Umea, Sweden) (Figure 1B). This particular harvesting head had a maximum opening of the upper delimbing knives of $64 \mathrm{~cm}$ and a maximum feed roller opening of $55 \mathrm{~cm}$ [21].

\subsection{Instrumentation and Sampling}

Initial field tests relied on conventional measurements of stump characteristics using rulers, string and a builder's level. However, severe difficulties were encountered when measuring the angles of the root flares since it was almost impossible to have a fixed reference point perpendicular to the ground and this for each $5 \mathrm{~cm}$ layer. For this reason, a TLS was instead chosen to collect field data consisting of 3D point clouds. The settings (resolution and quality) selected for this experiment corresponded to a point distance of $7.8 \mathrm{~mm}$ in a scan distance of $10 \mathrm{~m}$ with an average scan time of 190 seconds (not including site preparation and TLS setup) [22]. With these recording parameters, high accuracy was achieved while keeping the amount of data and scanning time appropriate.

Preliminary test scans indicated that moss and branches on the surface and sides of stumps could cause difficulties during data processing. Therefore, prior to the start of a scan, all sample stumps were cleared of moss and loose material (branches, leaves, dead material, etc.) from the cut surface down to the soil layer with the use of steel brushes, a procedure that took on average one minute per stump. Surrounding under-growth vegetation was also removed if it was deemed to hinder the upcoming scanning campaign. To facilitate the identification of the measured stumps within the point cloud, a wooden stake was inserted near each sampled stump prior to scanning.

Spheres of $145 \mathrm{~mm}$ diameter, automatically detectable by the processing software, were used in the field to facilitate merging point clouds originating from different scans. It was necessary that at least three spheres remained in the same location between two adjacent scans, thus permitting the software to triangulate the positions of the scanner. Prior to a scan, all positions of the spheres were verified by line-of-sight to ensure the scanner could detect the spheres from its current position.

To allow for exact measurements, the TLS was leveled at every scan position with the use of an adjustable tripod. Under ideal scanning conditions, a stump was scanned from three sides. One scan was always performed directly from the machine operating trail so that the horizontal distance between the trail centerline and the target stump could be measured. Whenever possible, the scans followed a diagonal pattern on one or both sides of the machine operating trail (Figure 2). In areas where dense vegetation or complex root systems were present, scanning frequency was increased accordingly to assure that all required data was captured. 


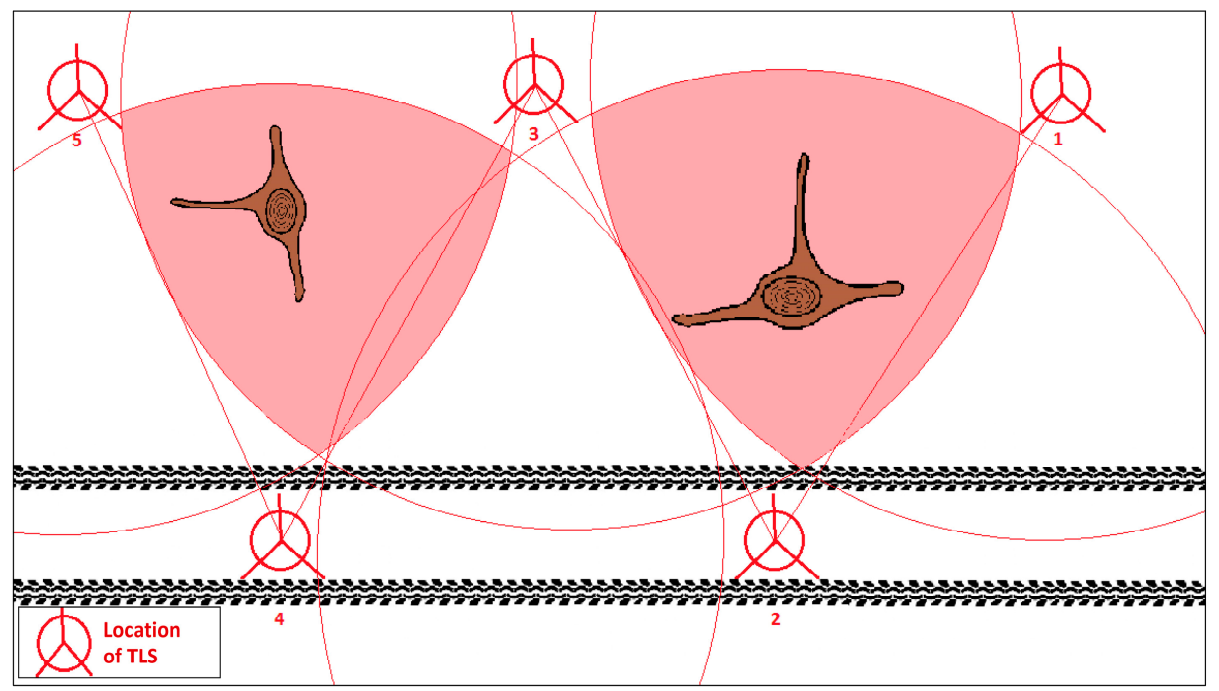

Figure 2. Schematic of an optimal scanning pattern to allow visualization and measurements of the stumps and machine operating trail.

\subsection{Data and Statistical Analyses}

Following the field campaign, data was examined using a point cloud processing, visualizing, and analyzing software. To perform exact measurements of the stump architecture, it was first necessary to create a mesh on the surface of the stump rather than try to obtain required measurements via the point cloud. This procedure, performed for all target stumps and corresponding machine operating trails, consisted of creating a triangular irregular network, which converted the point clouds into surfaces.

This study focused on characterizing four main parameters; stump diameter, stump height, root collar geometry, and distance to machine operating trail. Since it was of interest to understand the change in stump diameter from the cut surface down towards the soil surface, three different types of stump diameters will be discussed (diameter at cut surface, diameter at the $5 \mathrm{~cm}$ segment, and diameter at the $10 \mathrm{~cm}$ segment). All stump diameters have their starting point or starting horizontal plane on the top surface (cut surface) of the stump, which was in contact with the saw of the harvesting head. Unless otherwise specified, the diameter at cut surface is the origin $(0 \mathrm{~cm})$ and from this position, measurements were recorded in a vertical downward direction towards the ground in $5 \mathrm{~cm}$ increments. As an example, the further described $5 \mathrm{~cm}$ segment was the segment from the edge of the cut surface to a plane $5 \mathrm{~cm}$ below the cut surface (Figure 3E). Methods used to quantify stump characteristics are summarized below.

- Diameters: Similar to the method used by $[23,24]$, average stump diameters (mm accuracy), irrespective of their vertical position on the stump, were calculated using two outside bark diameter measurements (shortest and longest) extending through the geometric center of the stump (Figure 3C).

- Heights: Stump heights were measured with mm accuracy from the ground level on the high side (in reference to the ground) of the stump to the height at the geometric center at the cut surface [23] (Figure 3D).

- Root collar: To appropriately describe the root collar, every angle between the created vertical segments on the stump was measured to a horizontal line. The first angle was always the angle from the edge of the stump cut surface down to the $5 \mathrm{~cm}$ line. The angles were measured on top of the roots in a downward direction towards the ground (Figure 3F). Root collar was assessed in three segments; cut surface $(0 \mathrm{~cm})$ to $5 \mathrm{~cm}, 5$ to $10 \mathrm{~cm}$, and 10 to $15 \mathrm{~cm}$. For example, a $90^{\circ}$ angle would correspond to a root not extending beyond the natural taper of the stem. 
- Number of root flares per stump: Above-ground root flares were defined as visually discernable parts of a stump beyond its natural taper, which continuously extended down to the soil layer (as shown in Figure 3C).

- Distance to machine operating trail: The distance from a stump to the machine operating trail was measured from the geometric center of the stump to the centerline of the operation trail in a $90^{\circ}$ angle. To allow for this type of measurement, a line was generated following the middle of the trail and used as a reference for the $90^{\circ}$ measurements (Figure 3B).

The measurements described above only consider the shape of the top $15 \mathrm{~cm}$ of a stump as expressed from the cut surface downwards. In order to consider the shape of the entire stump, the diameters and root angles of a subsample of 100 stumps (randomly selected from the entire 202 stump data set) were also measured with the point of origin now beginning from the ground surface upwards in $5 \mathrm{~cm}$ layers until reaching the cut surface. In this subset, minimum diameters were measured similar to the functioning of a tree caliper. Thus, smaller diameters only caused by grooves or protrusions on a stump did not influence the caliper-type diameter measurements. The complimentary analysis was performed to better link the stump characteristics to the functioning of a harvesting head as it is being positioned at the base of a tree.

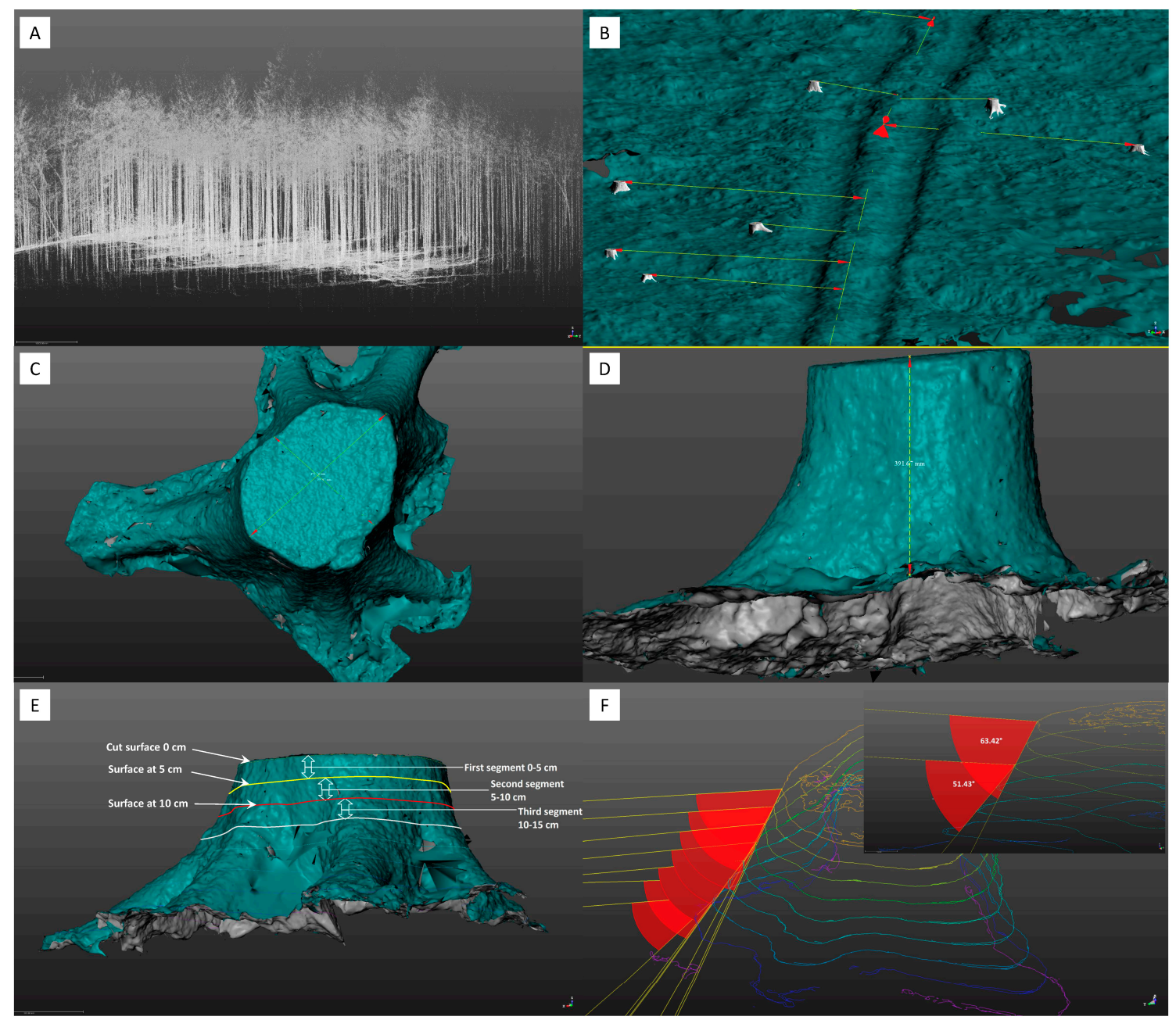

Figure 3. (A) Point cloud of the stand; (B) isometric-view of machine operating trail and stumps; (C) top-view of stump depicting the location of diameter measurements; (D) side-view of stump depicting height measurement; (E) side-view of stump showing the first three $5 \mathrm{~cm}$ segments and corresponding surfaces, and; (F) isometric-view of the angles measured for each layer and each root flare. 
For all ensuing measurements, data was transferred and analyzed in Minitab 17 and R Statistics. All response variables (diameters at different heights, height, distance to machine operating trail) were first tested for normality with the Anderson-Darling normality test. One-way ANOVAs were performed in Minitab with the diameter and height set as response variables and the number of roots per tree as the factor. R Statistics was used to obtain Pearson correlations. Additionally, a multiple linear regression analysis (ordinary least squares method) was performed in SAS 9.3 where the stump height was the dependent variable and the minimum diameter and average root angles at the cut surface and the number of root flares and the distance to the machine operating trail used as predictor variables. Outliers were identified by Cook's D, which combines information on the residual and leverage [25]. The normality of the residuals was proved by the Shapiro-Wilk W test for normality and homoscedasticity was tested by performing the White test. Lastly, multicollinearity was tested by looking at the variance inflation factor.

Another linear regression was performed with the data from the subsample of 100 stumps where measurements originated from the ground. The minimum diameter and the average of the angles of all roots were the explanatory variables and the distance to the cut surface the dependent variable. Here the average of the root angles of successive layers was assigned to the diameter between both segments. In addition, a quantile regression for this model was executed since they are useful in applications where extremes are important [26]. Therefore, the model should reveal if the variation of stump heights at the lower end are limited by stump diameter and the root collar and ultimately shed some light on if a threshold on the stump height imposed by the stump shape can be determined. In all statistical tests, a significance level of 0.05 was used.

\section{Results}

\subsection{Stump Characteristics}

\subsubsection{Diameter and Height}

All stump diameters, irrespective of their layers of measurement, (e.g., at cut surface, $5 \mathrm{~cm}$ or $10 \mathrm{~cm}$ below cut surface) followed a normal distribution based on the Anderson-Darling normality test (Figure $4 \mathrm{~A}-\mathrm{C}$ ). At the cut surface (Figure $4 \mathrm{~A}$ ), stump diameters ranged from $13.3 \mathrm{~cm}$ to $62.3 \mathrm{~cm}$ with an average of $37.9 \mathrm{~cm}$. As Figure $4 \mathrm{~A}-\mathrm{C}$ show, stump diameter increased as the measurement plane approached the soil surface with averages of $37.9,41.4$, and $44.0 \mathrm{~cm}$ for the cut surface, $5 \mathrm{~cm}$ segment, and $10 \mathrm{~cm}$ segment, respectively. At $10 \mathrm{~cm}$ below the cut surface, the total number of stumps with a diameter greater than $45 \mathrm{~cm}$ was 94 instead of 56 when only considering the diameters at the cut surface. That implies that 38 stumps (19\% of the total population) were reaching this diameter in only a $10 \mathrm{~cm}$ height difference on the vertical. It was apparent that the average diameter, minimum, and maximum was increasing as the measurement plane moved in a downward direction towards the soil surface. In fact, the diameters of stump increased on average by $9.2 \%$ between the 0 and $5 \mathrm{~cm}$ segments and by $4.6 \%$ between the 5 and $10 \mathrm{~cm}$ segments.

Unlike the frequency distribution of stump diameters, which all followed a normal distribution, stump heights were not normally distributed (Figure 4D). There was a higher frequency of stumps with heights between 15 and $25 \mathrm{~cm}$ as compared to the normal distribution curve. Stump heights varied between $8.8 \mathrm{~cm}$ and $57.1 \mathrm{~cm}$ with an average of $30.8 \mathrm{~cm}$.

\subsubsection{Root Collar}

On average, 3.5 root flares per stump were detectable (Figure 5A). Only seven stumps (3.5\%) showed no visible above-ground root flares meaning that the stump maintained somewhat of a cylindrical shape from the cut surface down to the soil layer. Due to the absence of visible root flares, those seven stumps were excluded from all upcoming root-related calculations. In general, most of the 
stumps (119 out of 195) had three or four root flares per stump, whereas only seven stumps had six or more visible above-ground root flares.
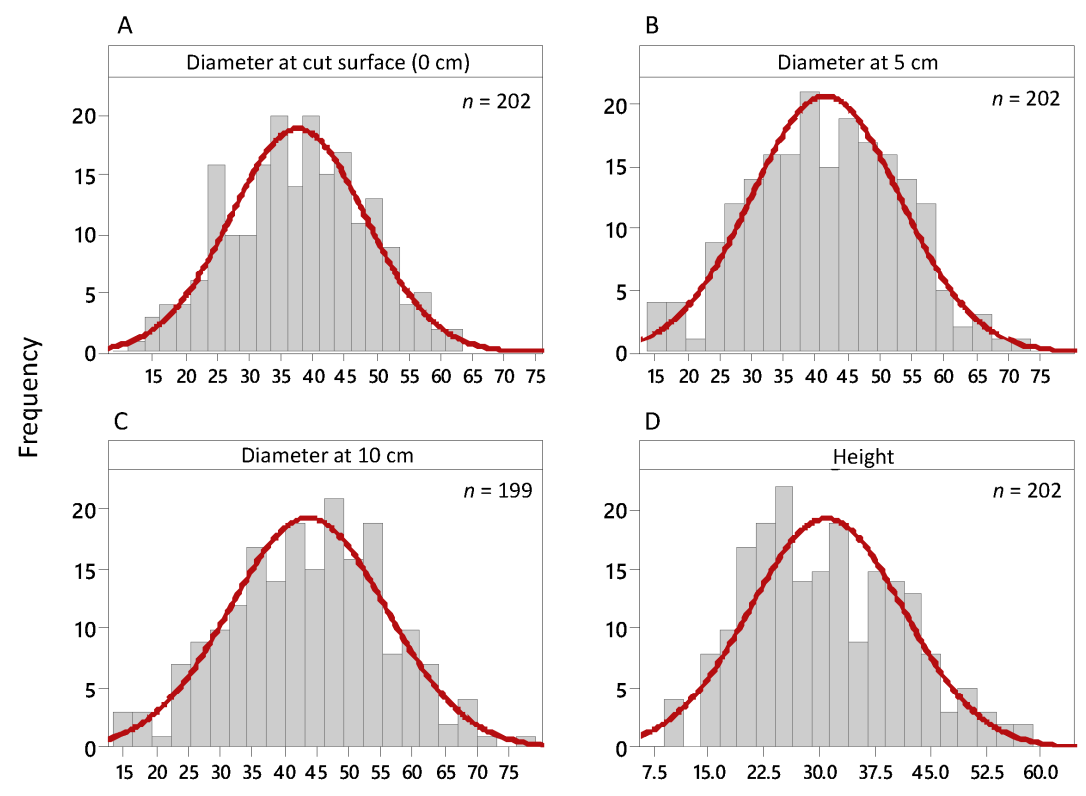

\begin{tabular}{lc}
\hline \multicolumn{2}{c}{ Diameter at cut surface $(0 \mathrm{~cm})$} \\
\hline Average & 37.9 \\
Minimum & 13.3 \\
Maximum & 62.3 \\
Std. dev. & 10.6 \\
\hline \multicolumn{2}{c}{ Diameter at $5 \mathrm{~cm}$} \\
\hline Average & 41.4 \\
Minimum & 15.2 \\
Maximum & 72.5 \\
Std. dev. & 11.6 \\
\hline \multicolumn{2}{c}{ Diameter at $10 \mathrm{~cm}$} \\
\hline Average & 44.0 \\
Minimum & 15.6 \\
Maximum & 77.3 \\
Std. dev. & 12.3 \\
\hline \multicolumn{2}{c}{ Height $(\mathrm{cm})$} \\
\hline Average & 30.8 \\
Minimum & 8.8 \\
Maximum & 57.1 \\
Std. dev. & 10.4 \\
\hline \multicolumn{2}{c}{}
\end{tabular}

$(\mathrm{cm})$

Figure 4. Frequency distributions for (A) stump diameters at cut-surface; (B) stump diameters at the $5 \mathrm{~cm}$ surface; (C) stump diameters at the $10 \mathrm{~cm}$ surface, and; (D) stump heights.
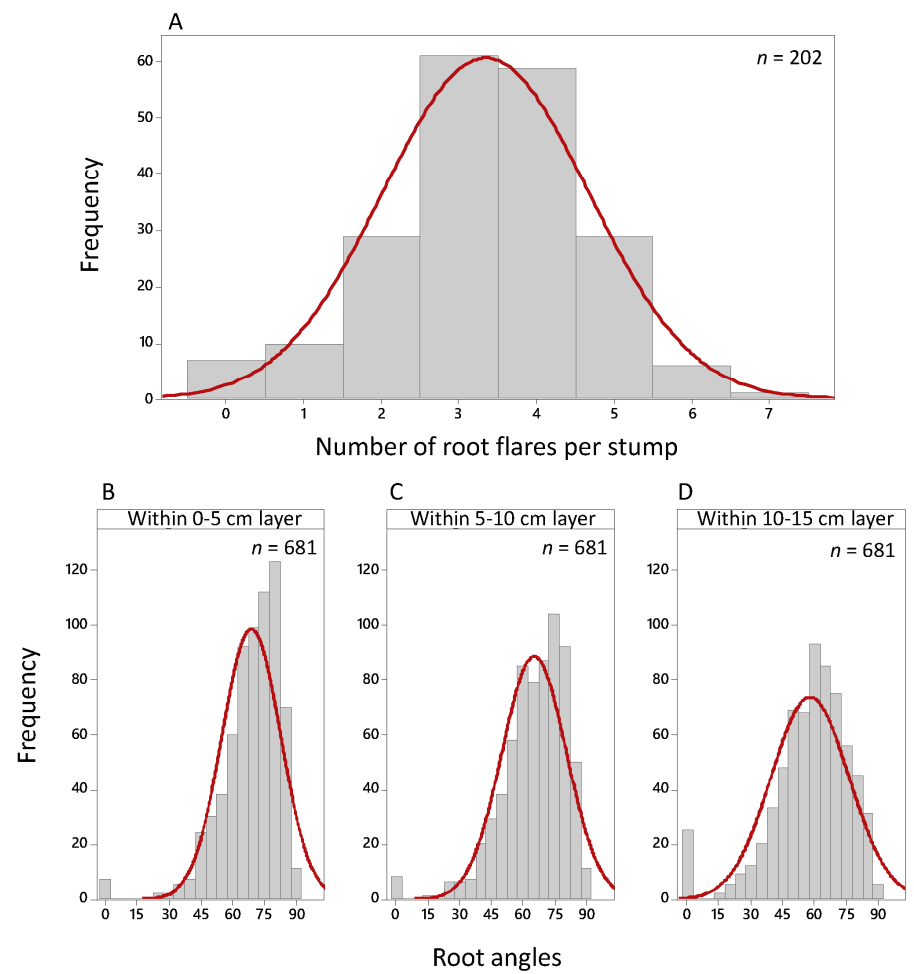

Figure 5. Frequency distributions for (A) number of root flares per stump; (B) root angles within the 0-5 cm layer; (C) root angles within the 5-10 cm layer; and (D) root angles within the 10-15 cm layer.

The 202 analyzed stumps provided 675 visually detectable above-ground root flares (as seen from the root collar) (Figure 5B-D). In general, a higher frequency of shallow root angles was measured as the plane used for calculations approached the ground. When focusing on root angles above $72.5^{\circ}$, 
the frequency of root flares decreased from $46 \%$ to $38 \%$ and down again to $20 \%$ for segments at cut surface, $5-10 \mathrm{~cm}$, and $10-15 \mathrm{~cm}$, respectively.

\subsection{Investigation of Relations}

\subsubsection{Relation between Stump Height/Diameter and Distance to Machine Operating Trail}

There did not seem to be any trend between stump diameter and distance to machine operating trail (Figure 6A), a result also supported by a very low Pearson correlation of $0.08(p=0.25)$. In fact, $75 \%$ of the stumps were located within $8 \mathrm{~m}$ from the centerline of the machine operating trails and only $12 \%$ were situated beyond $10 \mathrm{~m}$. As the point cloud in Figure $6 \mathrm{~B}$ shows, there was again no discernable linear correlation between stump height and distance to machine operating trail, as supported by a poor Pearson correlation of $0.06(p=0.40)$. There was in fact, high variability in stump height for a respective distance to trail.
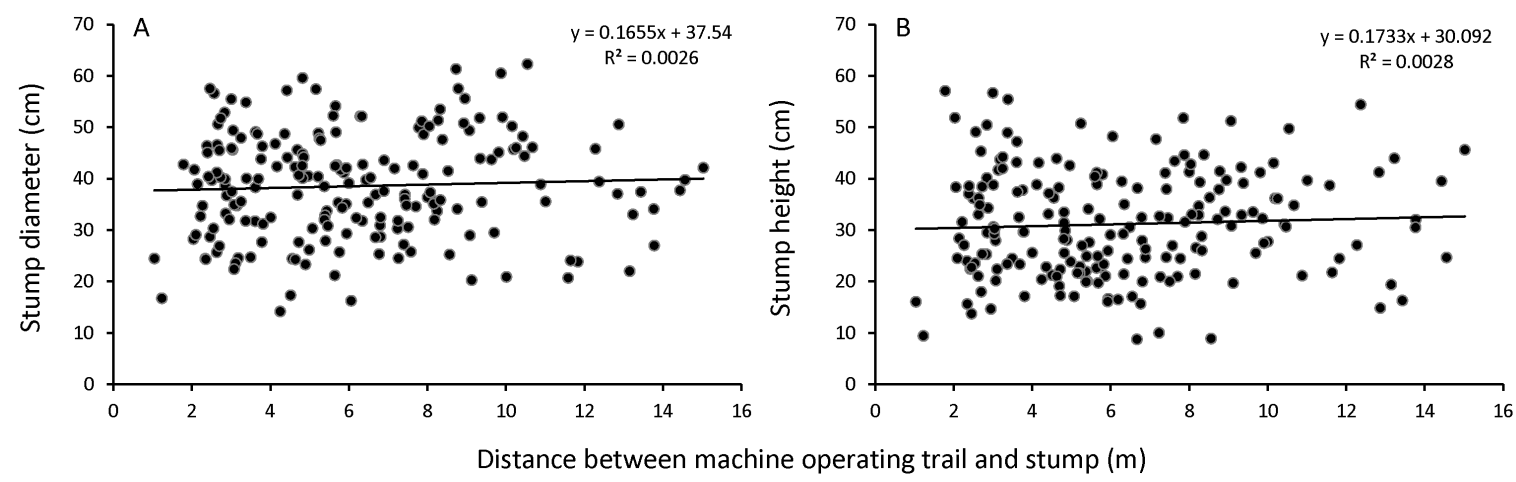

Figure 6. Relation between (A) stump diameter and distance to machine operating trail; and (B) stump height and distance to machine operating trail.

\subsubsection{Relation between Stump Diameter and Stump Height}

To determine if stump height was influenced by stump diameter, a possible correlation between both parameters was examined by plotting those two values against each other (Figure 7). To investigate the relationship, a Pearson correlation coefficient of $0.44\left(p=6.66 \times 10^{-11}\right)$ was calculated indicating that higher stumps tend to have larger diameters at the cut surface. The square of the obtained coefficient indicated that the stump diameter could explain $19 \%$ of the variation in stump heights.

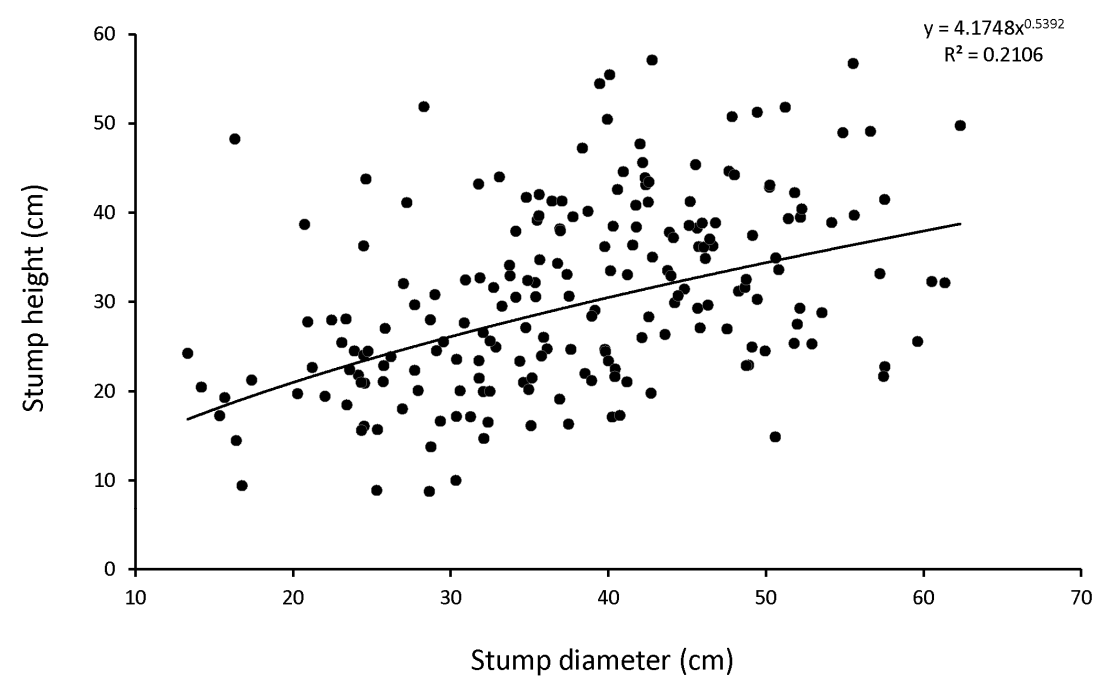

Figure 7. Relation between stump height and stump diameter. 


\subsubsection{Relation between Number of Root Flares per Stump and Stump Diameter/Height}

A statistically significant $(F=12.40, p=0.000)$ positive relationship existed between stump diameter and its corresponding number of root flares (Figure 8A). Average stump diameters increased from $20.4 \mathrm{~cm}$ when no above-ground root flares were visible within the root collar to $50.0 \mathrm{~cm}$ when six root flares were visible per stump. Stump height was also statistically influenced by the number of root flares per stump ( $F=2.71, p=0.01)$ with an increasing stump height as the number of root flares per stump increased (Figure $8 \mathrm{~B}$ ). When performing Fisher pairwise comparisons between the frequency of root flares per stump, statistically significant average stump heights were detected.
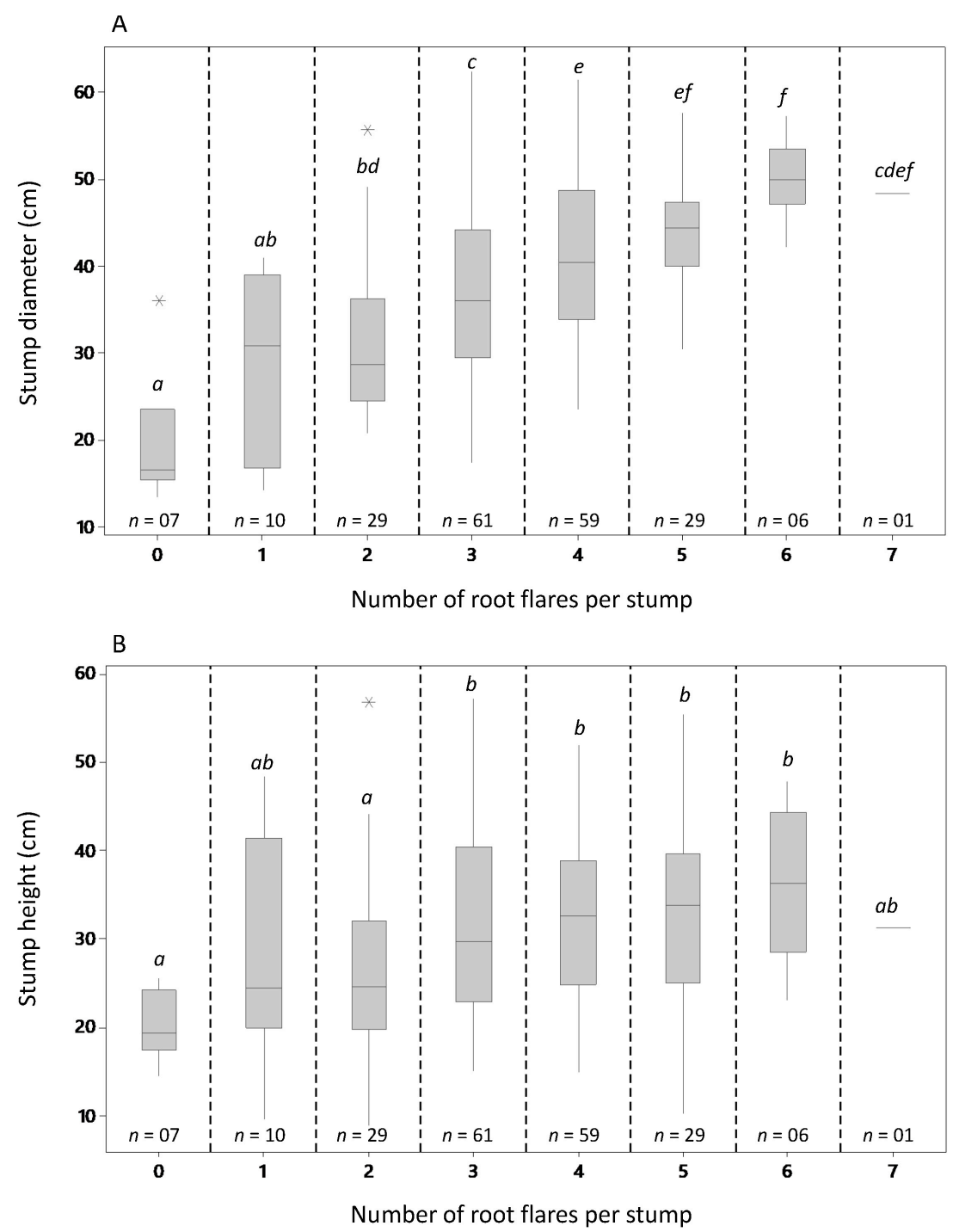

Figure 8. The influence of the number of root flares per stump on (A) stump diameter; and (B) stump height. Different lower case letters indicate a statistical difference at alpha 0.05 between the number of root flares per stump and stump diameter or height.

\subsubsection{Concurrent Effects on Stump Height}

The multiple regression model of stump height being predicted by diameter, root angle at the cut surface, number of root flares and distance to the machine operating trail revealed that the last two variable coefficients, were not significantly different from zero. Thus, these variables were excluded 
from the model, as well as 12 outliers. Both coefficients as well as the intercept of the following model (Equation (1)) were significantly different from zero $(\operatorname{Pr}>|\mathrm{t}|$ is $<0.0001)$ :

$$
\text { Stump height }(\mathrm{mm})=-326.39+0.813 \times \text { minimum diameter }(\mathrm{mm})+4.96 \times \text { root angle }\left(^{\circ}\right)
$$

The positive signs of the predictor variable coefficients were plausible and the adjusted R-square was 0.49 . Linearity between the predictor variables and stump height existed and the residuals were normally distributed. A variance inflation factor of 1.2 indicated no collinearity, while the White test indicated homoscedasticity.

The model was also tested with the average diameter and the maximum diameter at the cut surface instead of the minimum diameter. The coefficients were always significantly different from zero. However, the adjusted R-square was slightly lower with 0.46 in case of the average and 0.40 in case of the maximum diameter. In addition, a model was tested with the root angle and the number of root flares being the predictors of the stump height. However, in this instance, the coefficient of the variable root flare number was significantly different from zero but this model gained an adjusted R-square of only 0.14 and, thus, could hardly explain any variation of the stump heights.

\subsubsection{Relationship between Diameter and Root Angles and Their Distances to the Cut Surface}

The regression analysis of the minimum diameters and average root angles at all $5 \mathrm{~cm}$-segments from the ground upwards being the predictors and the distance to the cut surface as the response variable also showed a significant relationship. The coefficients of all parameters, minimum diameter, average root angle and intercept were significantly different from zero $(\operatorname{Pr}>|t|<0.0001)$. The model is (Equation (2)):

$$
\text { Distance to cut surface }(\mathrm{mm})=284.51+0.172 \times \text { minimum diameter }(\mathrm{mm})-3.997 \times \text { root angle }\left(^{\circ}\right)
$$

An increasing diameter as well as a decreasing root angle as the distance from the cut surface downwards increased was plausible. The adjusted R-square was 0.61 and linearity between the predictor variables and the distance to the cut surface existed. The Shapiro-Wilk W test provided a $p$-value of 0.0640 , thus, still indicating a normal distribution of the residuals. The variance inflation factor of 2.1 indicated no collinearity of the parameters, whereas the White test indicated that heteroscedasticity was highly significant $(\mathrm{Pr}>\mathrm{ChiSq}$ is $<0.0001)$ (Figure 9.) There is a sharp edge at the lower end of both axes.

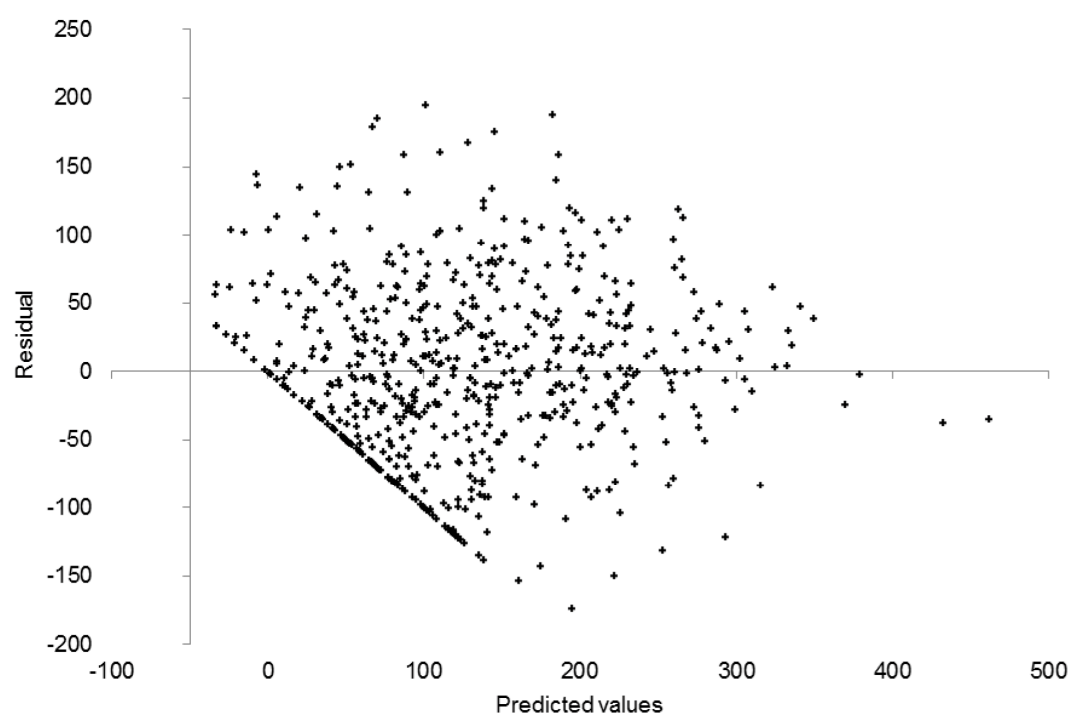

Figure 9. The residuals plotted against the predicted values. 
The quantile regression for the $10 \%$-quantile of the data delivered the following coefficients (Equation (3)):

Distance to $c u t$ surface $(\mathrm{mm})=124.1323+0.2112 \times$ minimum diameter $(\mathrm{mm})-3.0189 \times$ root angle $\left(^{\circ}\right)$

All coefficients were significantly different from zero. Figure 10 shows the plane spanned by this equation. The border between the green and purple area identified the threshold of the minimum diameter and the average root angles at the cut surface and thus the theoretical threshold for minimum stump height.

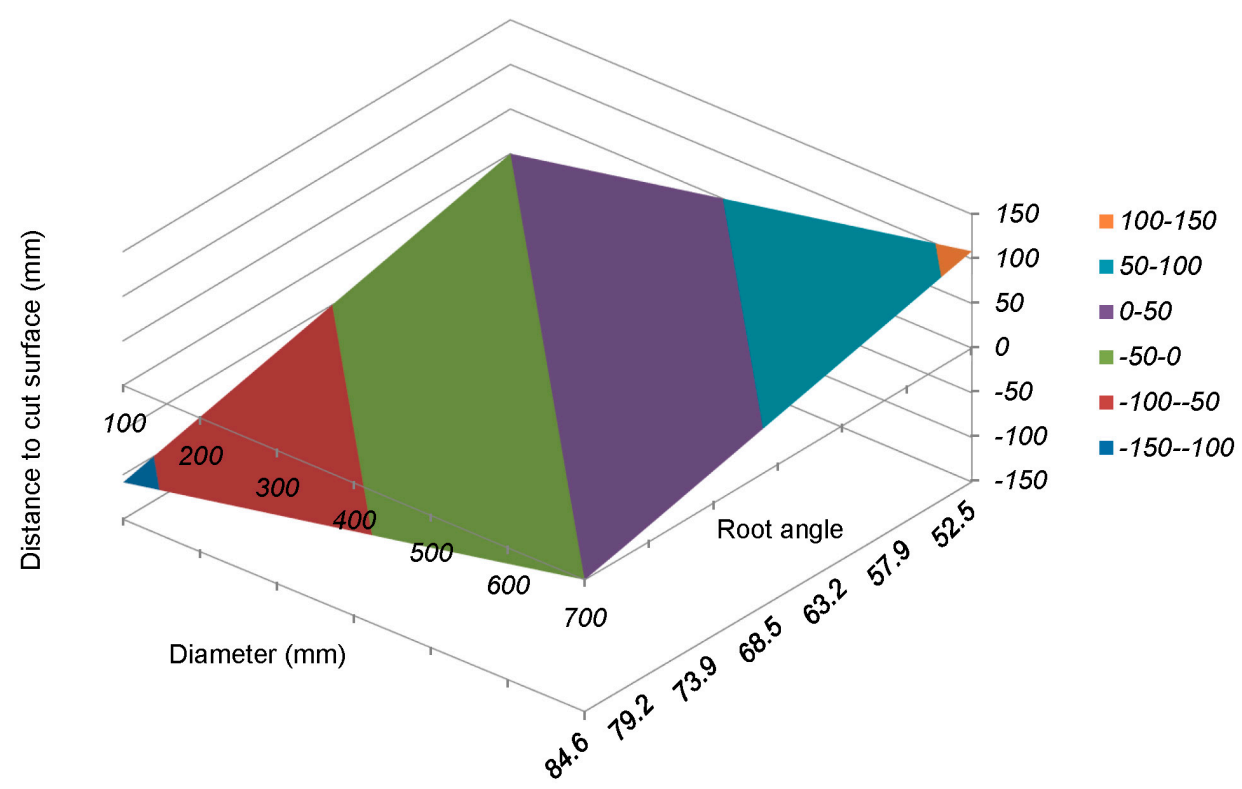

Figure 10. The plane of the $10 \%$-quantile presented in a three-dimensional diagram (stump diameter, root angle, and the distance to cut surface).

Table 1 lists the threshold of diameters and root angles at a distance of zero to the cut surface. For a given diameter, the root angle at the cut surface could be steeper, but not lower than shown in Table 1. Conversely, for a given root angle the minimum diameter could be smaller, but not larger than listed in the table. Only $16 \%$ of the stumps had a root angle at the cut surface steeper than $79^{\circ}$. Only two stumps of the subsample exceeded a minimum diameter of $600 \mathrm{~mm}$. No stump was located beyond the threshold of both, $600 \mathrm{~mm}$ and $79.2^{\circ}$. This corresponded well to the technical configuration of the harvesting head studied. The opening width of the feed rollers was $550 \mathrm{~mm}$, thus indicating the limit for gripping a tree.

Table 1. The threshold of diameters and root angles at the cut surface.

\begin{tabular}{cccccccc}
\hline Minimum Diameter (mm) & 100 & 200 & 300 & 400 & 500 & 600 & 700 \\
\hline Root Angle $\left(^{\circ}\right)$ & 52.5 & 57.9 & 63.2 & 68.5 & 73.9 & 79.2 & 84.6 \\
\hline
\end{tabular}

Figure 11 shows the frequency of stumps at different length classes indicating the length of stump sections being higher than the $10 \%$-quantile. This analysis implied that $62 \%$ of the stumps could have theoretically been cut lower to the ground. The difference between the 10\%-quantile and the actual height of the stump could be used as an indicator of unexploited volume since in theory, cutting the tree lower (thus providing a lower stump height) would entail a longer stem than if the tree was cut at a higher position. The length of this potentially unexploited stem wood was mostly shorter than $16.0 \mathrm{~cm}$ with an overall average of $9.9 \mathrm{~cm}$ corresponding to a total volume of $8.5 \mathrm{dm}^{3}$. Considering all 
stumps, and applying the results from the $10 \%$-quantile analysis, about $0.4 \%$ of the core wood of all removed trees was probably unexploited during the mechanized operations.

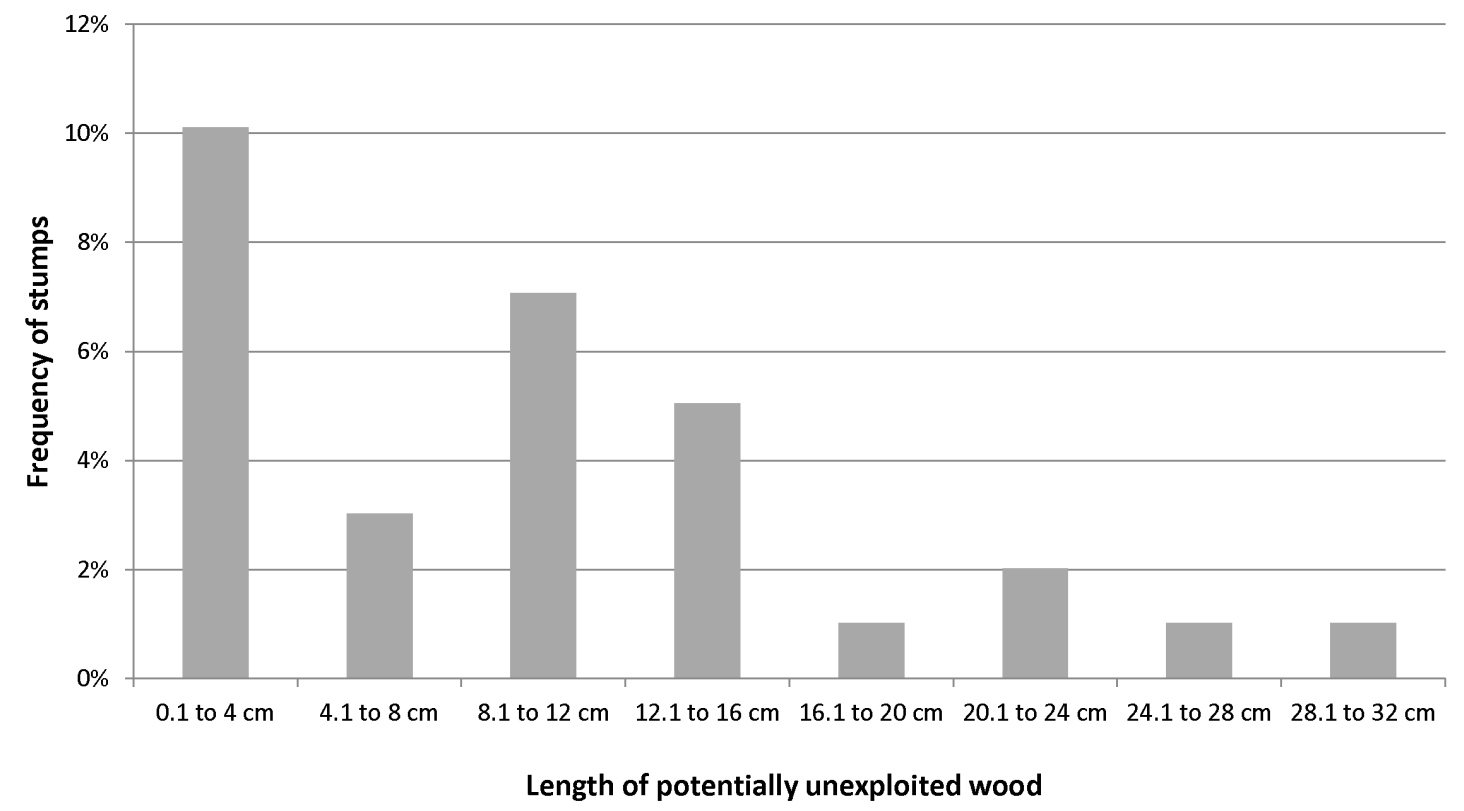

Figure 11. The frequency of stumps presented in classes referring to the length of potentially exploited wood derived by the $10 \%$-quantile analysis.

\section{Discussion}

\subsection{Stump Characteristics}

The dataset of 202 stumps supported a positive trend of increasing stump height with an increase in stump diameter. This implies that for those stumps that were close to the maximum operating capability of the harvesting head, stump diameter should have an impact on stump height. Despite the relatively small stump sizes in relation to the maximum opening of the harvesting head, high variation in stump height was observed suggesting that the height at which a stump is cut during mechanized harvesting operations might not be entirely related to physical parameters of the stump or the maximum opening of the harvesting head.

\subsection{Root Flares and Root Collar}

A positive linear trend could be noticed between the number of root flares per stump and stump height. A much stronger relationship was apparent between the number of root flares per stump and stump diameter. The trend through the entire dataset can be explained as large diameter trees often grow supporting roots to stabilize themselves against side-pressure associated with wind forces. All stumps with no visible above-ground root flares in the dataset had, therefore, relatively small diameters. The development of the trend implied that, when a certain above-ground root flare mass was grown, this effect was getting smaller. By comparing the diameter segments, a second trend could be seen. The point clouds were moving to the top right corner with an increase in diameter class. This also seemed to be caused by the increasing diameter and not by flatter angles. The initial trend was similar throughout the diameter classes but was less apparent at higher diameters.

\subsection{Machine Operating Trail}

At the onset of the study, we anticipated that as the distance from a stump to the machine operating trail increased, that the operator visibility would be hindered and the lifting force of the boom would decrease, both contributing to higher stumps. However, the horizontal distance between 
sampled stumps and the machine operating trail did not influence diameter and height of the stumps that were scanned. Of course, the diameter of a tree influences its weight, which can become a limiting factor in relation to the maximum reach of the harvester and its ability to perform adequate and safe felling, but for the study, a consistent deviation of all stump diameters and heights up to the maximum reach of the boom was reported. For some instances, distances measured between the center of the machine operating trail and the center of the sample stumps was greater than the reach of the harvester boom. It is possible that on some occasions, the harvester operator performed so-called poke-ins or pockets with the harvester to be able to reach trees located further away from the trail. With the presence of brush mats coupled with a single machine pass, these pockets can be difficult to detect in the scan. The likelihood of this scenario occurring was increased since operations were performed following a wind-throw. In such conditions, all trees were felled and processed with machines to ensure the safety of all workers. Second, it is also possible that the bird's eye view projection of the machine operating trail centerline was not located precisely because of too high and dense vegetation on the trail at the end of the field campaign. Therefore, in further projects it is recommended to scan early at the beginning of the growing season or control competitive vegetation such as Himalayan balsam (Impatiens glandulifera Royle). This particular vegetation became a significant problem by covering up the operating trails and masking them in the scans.

\subsection{Concurrent Effects on Stump Height}

The diameter of a stump and the shape of the root collar at the cut surface together had a significant effect on stump height. The model explained even half of the variation of stump heights. The minimum diameter contributed more to the explanation of stump height variation than the average or the maximum diameter. This was plausible because it was rather the minimum diameter which limited the grabbing of the tree by the harvesting head, since the later could be swiveled during the positioning at the base of a tree.

Somewhat contradictory appeared the observation that the stump height increased with the diameter, as well as the number of root flares, but in the multiple regression model the number of root flares revealed no significance. The regression model showed no critical multicollinearity of the diameter and the number of root flares when both parameters were included into the model. But in a model with the predictors "root angle" and "number of root flares", the coefficient of the root number also became significantly different from zero. However, this model without the predictor "minimum diameter" had an adjusted R-square of only 0.14. Thus, the number of root flares other than the diameter could explain hardly any variation of the stump heights.

The minimum diameters and average root angles at all $5 \mathrm{~cm}$-segments from the ground upwards seemed to have a significant relation to their distance to the cut surface. However, this model violated an important assumption of linear regression models, because the residuals were not homogenous as expressed by the scatterplot of the residuals showing a sharp edge. Nevertheless, this edge was artificial, because no negative distances to the cut surface were allowed. The edge was marked by the straight line where the negative residuals equaled the predicted values. At a predicted distance of e.g., $100 \mathrm{~mm}$ to the cut surface the minimum residual that could occur was $-100 \mathrm{~mm}$. The deviation to the negative side could not be greater, because no negative distances to the cut surface were in the data set. If we had measured the tree before logging, we could have determined the distances from above the cut surface too and these distances could have been introduced as negative values into the model. Thus, we would have received a homogenous distribution of the residuals. There might also be certain physical factors located higher than the cut surface that could have influenced stump height but were not considered in the study since only the stump sections were scanned. Further investigations should also consider the shape of the tree before harvesting via a scan of the first 2-3 meters from the ground surface.

A quantile regression applied to the dataset of the last model revealed the lower limit of stump heights, which was imposed by the diameter and the root collar. The model disclosed a limit of 
minimum diameters at the cut surface of $600 \mathrm{~mm}$. The limiting factor of the particular harvesting head was the opening width of the feed-rollers, which was $550 \mathrm{~mm}$. However, this point was not detected as it was located on the log rather than on the measured stump. The center of the feed-rollers was at a distance of approximately $0.75 \mathrm{~m}$ from the level of the saw bar. Therefore, a diameter at the cut surface slightly wider than the maximum opening of the feeding rollers was plausible.

Almost one-third of all stumps could have been cut at a lower level according to the observed limit. There might have been reasonable explanations for cutting the trees at higher levels but they could not be assigned to the size of the stump and the root collar. In the study, the amount of wood which was not exploited was low ( $0.4 \%$ of core wood) but could easily increase in the case of higher stumps. We do not know the variation between different logging operations. Perhaps the stump heights were close to the optimum in our case study and our case is far away from the average. Considering a unit price of $100 € / \mathrm{m}^{3}$ for Norway spruce sawlog of high quality and an average tree diameter of $1 \mathrm{~m}^{3}$, a monetary loss of about $0.40 € / \mathrm{m}^{3}$ could be anticipated. At first sight, this might seem quite trivial but when considering that about $60 \%$ of the harvests on public forests (approx. 3,000,000 $\mathrm{m}^{3}$ ) in Bavaria are performed with fully-mechanized systems, the potential value loss could be considerable.

\subsection{Review of the Applied Methods}

The thresholds detected in this study cannot be generalized as they refer to the specific configuration of the harvesting head. A harvesting head with a greater opening width of the feed-rollers should allow larger diameters at the cut surface. In other cases, the limiting factor might be the width of the lower knifes of the harvesting head. Further studies with different harvesting heads could disclose the effect of the configuration on the cutting level. We recommend scanning the trees before logging and the stumps after logging. Through this method, the shape of the stem above the cutting level could also be included in the model and the distribution of the residuals should be homogenous. Additional attributes of a tree above the cut surface could also be included in the explanatory model.

Within this study, the operator's line-of-sight and visibility within the harvester cabin was not considered as the field measurement campaign was performed after the completion of the operations. Nevertheless, as one scan was always taken from the intended machine operating trail (clear visibility towards the stump was indispensable), a clear line-of-sight was present for all measured stumps. In a further approach, recording the angle formed between the boom being extended from the machine towards the stump could provide additional information on the position of the harvester and the associated visibility of the operator, thus, further helping to understand the effect of visibility on stump height.

Measuring the minimum diameter at grooves of the contour of the cut surface delivered results which certainly do not refer to the configuration of the harvesting head. In this study, minimum diameters were measured like a caliper measures only for the subsample of 100 stumps. Further studies should measure the diameter in this way, too.

Lastly, we could have chosen other predictor variables. We also could have taken the minimum root angle instead of the average. In fact, we tested different models but the average angle of all roots at one layer delivered better results measured by R-square as compared to the minimum value.

\section{Conclusions}

In total, 202 mechanically harvested stumps were examined through the use of a TLS, which proved to be a valuable tool for data recording and ensuing assessment. The distance between a stump and the nearest machine operating trail showed no influence on stump height nor did it seem to affect stump diameter under the tested conditions of relatively flat terrain. The diameter alone was able to explain about $20 \%$ of the variation in stump heights. The number of above-ground root flares per stump had no noticeable influence on stump height but stump diameters were greater with an increase in the number of roots. The diameter of a stump and the shape of the root collar at the cut 
surface together had a significant effect on stump height as the model explained half of the variation of stump heights.

Future studies with expanded data sets could shed more light onto the influence of root collar geometry particularly if they are conducted to include physical features of the bottom log on stump height following mechanized forest operations.

Author Contributions: All authors conceived the experiment while E.R.L. and J.B.H. performed the experiments; All authors analyzed the data and contributed to the written manuscript.

Acknowledgments: The authors wish to extend gratitude to Johannes Windisch, Philipp Gloning and Fabian Schulmeyer for providing insight during the conception of the project. We also wish to thank Michael Miesl for his assistance during the field work and Siegfried Waas for preliminary data preparation.

Conflicts of Interest: The authors declare no conflict of interest.

\section{References}

1. Bayerische Staatsforsten. Statistikband; Bayerische Staatsforsten: Regensburg, Germany, 2017; p. 30.

2. Gardiner, B.; Blennow, K.; Carnus, JM.; Fleischer, P.; Ingemarson, F.; Landmann, G.; Lindner, M.; Marzano, M.; Nicoll, B.; Orazio, C.; et al. Destructive Storms in European Forests: Past and Forthcoming Impacts; Final Report to European Commission-DG Environment; European Forest Institute: Joensuu, Finland, 2013; p. 139.

3. Nick, L. Forstmaschinenstatistik 2007-noch einmal ein Erfolgsjahr. Forsttech. Inf. 2008, 11, 117-119.

4. Visser, R.; Stampfer, K. Expanding ground-based harvesting onto steep terrain: A review. Croat. J. For. Eng. 2015, 2, 321-331.

5. Food and Agriculture Organization of the United Nations. Code of Practice for Forest Harvesting in Asia-Pacific. Pre-Harvest Field Preparation. Available online: http:/ /www.fao.org/docrep/004/AC142E/ ac142e0d.htm (accessed on 21 November 2016).

6. Hilker, T.; van Leeuwen, M.; Coops, N.C.; Wulder, M.A.; Newnham, G.J.; Jupp, D.L.B.; Culvenor, D.S. Comparing canopy metrics derived from terrestrial and airborne laser scanning in a Douglas-fir dominated forest stand. Trees 2010, 24, 819-832. [CrossRef]

7. Moorthy, I.; Miller, J.R.; Hu, B.; Chen, J.; Li, Q. Retrieving crown leaf area index from an individual tree using ground based lidar data. Can. J. For. Res. 2008, 34, 320-332.

8. Strahler, A.H.; Jupp, D.L.B.; Woodcock, C.E.; Schaaf, C.B. Retrieval of forest structural parameters using a ground based lidar instrument. Can. J. For. Res. 2008, 34, 426-440. [CrossRef]

9. Bao, Y.; Ni, W.; Wang, D.; Yue, C.; He, H.; Verbeeck, H. Effects of tree trunks on estimation of clumping index and LAI from HemiView and Terrestrial LiDAR. Forests 2018, 9, 144. [CrossRef]

10. Hopkinson, C.; Chasmer, L.; Young-Pow, C.; Treitz, P. Assessing forest metrics with a ground-based scanning lidar. Can. J. For. Res. 2004, 34, 573-583. [CrossRef]

11. Watt, P.J.; Donoghue, D.N.M. Measuring forest structure with terrestrial laser scanning. Int. J. Rem. Sens. 2005, 26, 1437-1446. [CrossRef]

12. Henning, J.; Radtke, P. Detailed stem measurements of standing trees from ground-based scanning Lidar. For. Sci. 2006, 52, 67-80.

13. Maas, H.G.; Bienert, A.; Scheller, S.; Keane, E. Automatic forest inventory parameter determination from terrestrial laser scanner data. Int. J. Rem. Sens. 2008, 29, 1579-1593. [CrossRef]

14. Yu, X.; Liang, X.; Hyyppä, J.; Kankare, V.; Vastaranta, M.; Holopainen, M. Stem biomass estimation based on stem reconstruction from terrestrial laser scanning point clouds. Rem. Sens. Let. 2013, 4, 344-353. [CrossRef]

15. Yan, Y.; Xia, M.; fan, S.; Zhan, M.; Guan, F. Detecting the competition between Moso bamboos and broad-leaved trees in mixed forests using a terrestrial laser scanner. Forests 2018, 9, 520. [CrossRef]

16. Bayer, D.; Siefert, S.; Pretzsch, H. Structural crown properties of Norway spruce (Picea abies L. Karst.) and European beech (Fagus sylvatica L.) in mixed versus pure stands revealed by terrestrial laser scanning. Trees 2013, 27, 1035-1047. [CrossRef]

17. Bayer, D.; Pretzsch, H. Reactions to gap emergence: Norway spruce increases growth while European beech features horizontal space occupation-Evidence by repeated 3D TLS measurements. Silva Fennica 2017, 51, 20. [CrossRef] 
18. Beyer, R.; Bayer, D.; Letort, V.; Pretzsch, H. Validation of a functional-structural tree model using terrestrial Lidar data. Ecol. Model. 2017, 2017. 357, 55-57. [CrossRef]

19. Pyörälä, J.; Kankare, V.; Rikala, J.; Holopainen, M.; Sipi, M.; Hyyppä, J.; Uusitalo, J. Comparison of terrestrial laser scanning and X-ray scanning in measuring Scots pine (Pinus sylvestris) branch structure. Int. J. For. Eng. 2018, 33, 291-298. [CrossRef]

20. Liski, J.; Kaasalainen, S.; Raumonen, P.; Akujärvi, A.; Krooks, A.; Repo, A.; Kaasalainen, M. Indirect emissions of forest bioenergy. Detailed modeling of stump-root systems. GCB Bioenergy 2014, 6, 777-784. [CrossRef]

21. Komatsu Forest. 360.2 Spezifikationen. 2015. Available online: http://www.komatsuforest.de/default.aspx? $\mathrm{id}=10778 \&$ mode=specs\&rootID=\&productId=22.07.2015 (accessed on 24 May 2018).

22. FARO Technologies Inc. FARO Laser Scanner Focus3D User Guide; FARO: Lake Mary, FL, USA, 2015; p. 186.

23. Han, H.-S.; Renzie, C. Effect of ground slope, stump diameter, and species on stump height for feller-buncher and chainsaw felling. Int. J. For. Eng. 2005, 16, 81-88. [CrossRef]

24. Ministry of Forests, Lands and NRO. Cruising Procedures Manual; British Columbia: Victoria, Canada, 2014; Volume 6. Available online: https:/ /www.for.gov.bc.ca/ftp/hva/external/!publish/web/manuals / cruising/chapters/Ch6.pdf (accessed on 21 November 2016).

25. UCLA: Statistical Consulting Group. Introduction to SAS. 2017. Available online: https://stats.idre. ucla.edu/sas/webbooks/reg/chapter2/regressionwith-saschapter-2-regression-diagnostics/ (accessed on 28 May 2018).

26. Colin, C. An Introduction to Quantile Regression and the QUANTREG Procedure; Nelson, G.S., Ed.; 2005; pp. 213-230. Available online: http://www2.sas.com/proceedings/sugi30/toc.html (accessed on 20 June 2018).

(C) 2018 by the authors. Licensee MDPI, Basel, Switzerland. This article is an open access article distributed under the terms and conditions of the Creative Commons Attribution (CC BY) license (http:/ / creativecommons.org/licenses/by/4.0/). 